\title{
Evaluating the impact of single exit pricing (SEP) on medicine product withdrawal from the private healthcare market in South Africa
}

\author{
K Naidoo, BPharm, MPharm; F Suleman, BPharm, MPharm, PhD \\ Discipline of Pharmaceutical Sciences, School of Health Sciences, Westville Campus, University of KwaZulu-Natal, Durban, South Africa
}

Corresponding author: F Suleman (sulemanf@ukzn.ac.za)

Background. The introduction of medicine pricing policies in South Africa (SA) in the form of single exit pricing (SEP) provided a mechanism to improve medicine price transparency and reduce the medicine price and inflation. However, regulation of medicine prices may have further unforeseen effects on the availability of medicine. This research presents the impact of SEP on discontinuation of medicine products on the private healthcare market in SA.

Objectives. To evaluate the impact of SEP legislation on the availability of medicines in the SA private health sector in terms of withdrawal of medicines from the market.

Methods. A descriptive, quantitative analysis of all registered medicines on the SA market by stock-keeping units (SKUs) was done to establish medicine products that were withdrawn from the market by SKUs during a 14-year period (2001 - 2014).

Results. A total of 152 manufacturers discontinued 3691 SKUs between 2001 and 2014. The mean number of discontinuations per generic manufacturer was 22.34 (standard deviation (SD) 58.11), while innovator manufacturers discontinued a mean of 27.61 (41.89). The largest number of SKUs were commercially withdrawn in 2002 ( $n=603)$, followed by discontinuations in $2003(n=463)$ and $2004(n=407)$. There was a negative correlation between number of discontinued SKUs per year and SEP increase (Pearson's correlation coefficient $r-0.414$; $p=0.14)$. The results showed that SEP and a transparent pricing policy may have had an impact on SKU withdrawal from the market prior to SEP implementation.

Conclusions. The result of reduced product availability on the market and its impact on the cost and quality of healthcare to the patient need to be regularly monitored and evaluated to ascertain if direct price regulations achieve the intended outcomes. Other intended or unintended effects on pharmaceutical market dynamics should also be evaluated.

S Afr Med J 2021;111(5):444-447. https://doi.org/10.7196/SAMJ.2021.v111i5.15297

South Africa (SA)'s apartheid era saw disparities in the public and private health sectors. ${ }^{[1]}$ By 1990, the private sector was responsible for $80 \%$ of SA's total medicine expenditure. ${ }^{[2]}$ In 1994, the new democratically elected government, faced with problems, e.g. lack of equity in access to essential medicines and rising medicine prices, decided to tackle these problems systematically through the development and implementation of the national drug policy. ${ }^{[2]}$

In December 1997, the SA government promulgated legislation aimed at lowering the cost of medicines to all South Africans. ${ }^{[3]}$ This legislation made provision for the establishment of the Medicine Pricing Committee (MPC), which makes recommendations on the introduction of a transparent pricing system for all medicines sold in SA. ${ }^{[3]}$ In 2004, 'Regulations relating to a transparent pricing system for medicines and scheduled substances' were promulgated. ${ }^{[4]}$ These new regulations introduced single exit pricing (SEP) as a mechanism to improve medicine price transparency. The overall aim of SEP was to improve access to medicines by reducing prices of innovator and generic medicines and to control price increases. ${ }^{[4]}$

Although medicine pricing policies may aim to keep medicines accessible, regulating medicine prices may have various effects on the availability of medicine. ${ }^{[5,6]}$ It may increase or decrease or have a negligible effect on the availability of medicines to the patient. Pricing regulations have led to a lower level of new medicine introductions and to market withdrawal of some products, which may increase the vulnerability of the pharmaceutical market to medicine shortages. ${ }^{[5,6]}$ The impact of medicine price controls has been extensively described in high-income markets with welldeveloped universal health coverage systems and those that exercise price control on predominately reimbursed medicines. ${ }^{[7-9]}$ Pricing policies in the European Union (EU) have successfully reduced the cost of medicines for health funders and patients. These policies have also led to unforeseen factors, such as parallel export of medicines from lower-priced markets, a stricter supply chain with regard to keeping smaller inventories and reducing costs, and some manufacturers removing medicines or not introducing them to lower-priced markets. ${ }^{[5,6]}$

There is limited literature addressing the impact of medicine price controls in low- and middle-income countries, where a significant portion of patients are without healthcare insurance and incur considerable out-of-pocket expenditure for medicines. ${ }^{[10]}$ In the SA private sector context, this is further compounded by the uniqueness of the price controls adopted, where all medicine prices (whether reimbursed or not) are controlled (with the exception of schedule 0 medicines, which are exempt). The introduction of SEP in SA realised an average reduction of $22 \%$ in the price of medicines; however, a consistent pricing benefit was not realised by consumers. ${ }^{[1]}$ Research on community pharmacies by Pretorius ${ }^{[1]}$ further established that, with a reduction in overall gross profit generated by pharmacies, the pressure on the business environment was evident.

A survey conducted by Naudé and Luiz in $2013^{[12]}$ found that price controls in SA reduced profit margins on medicines that are sold locally, which resulted in pressure on suppliers to increase their 
economies of scale to reduce the cost per unit produced. Importantly, they also observed that some companies discontinued the production of certain products, as it no longer remained economically viable to produce these locally. Our research presents the impact of medicine price controls in the form of SEP on medicine product discontinuation on the SA private healthcare market. For this study, medicine discontinuation also refers to medicine withdrawal. Therefore, the objective of the study was to evaluate the impact of SEP legislation on the availability of medicines on the private health sector market in SA in terms of withdrawal of medicines from the market.

\section{Methods}

A quantitative analysis of all registered medicines on the SA private sector market by stock-keeping units (SKUs) was done to identify medicine products withdrawn from the market by SKUs. An SKU is a service identification code for a store or product, often portrayed as a machine-readable barcode that helps to track the item for an inventory. An SKU does not need to be assigned to physical products in an inventory. Different pack sizes of a product are defined by separate SKU codes.

A comprehensive list of all marketed medicines on the SA private sector market by SKUs was obtained from a medical database managed by medical data specialists (Medprax, SA), who supply essential up-to-date medicine price data for the SA healthcare industry. The dataset consisted of all medicines by SKU, schedule $1-8$, from 2001 to 2014, which were marketed, withdrawn or flagged for withdrawal (in the system) at a time point within the period described. Schedule 0 products were excluded, as these are exempt from price controls.

Data were entered into Microsoft Excel, version 2016 (Microsoft Inc., USA) in a format developed for this study. Discontinued SKUs were identified, and the subset was then analysed. The data were analysed and summarised descriptively using frequency tables and graphs. Discontinued SKUs were grouped by innovator and generic companies and then by anatomical therapeutic chemical (ATC) classification, and summarised descriptively using frequency tables and graphs. All statistical procedures were performed in Microsoft Excel.

\section{Ethical approval}

The study was granted ethical clearance by the Human and Social Sciences Research Ethics Committee, University of KwaZulu-Natal, Durban, SA (ref. no. HSS/0154/013).

\section{Results}

A total of 152 manufacturers discontinued at least one SKU between 2001 and 2014. The majority of identified manufacturers produced only generic medicine $(n=96 ; 63.16 \%)$ and are classified as generic manufacturers. Manufacturers producing patent medicines accounted for $36.84 \%(n=56)$ and were classified as innovator manufacturers (Table 1). A total of 3691 SKUs was discontinued during the study period. Innovator manufacturers accounted for $41.89 \%$ ( $n=1546)$ of all SKUs discontinued, with generic manufacturers being responsible for 2145 (58.11\%) discontinuations (Table1).

The analysis showed that the number of discontinued SKUs ranged from 123 to 603. The mean number of discontinuations for generic manufacturers was 22.34 (standard deviation (SD) 58.11), while innovator manufacturers discontinued a mean of 27.61 (41.89). The $t$-test showed that there was no statistically significant difference between the means $(t-0061 ; p=0.27)$ (Table 2). The largest number of SKUs was commercially withdrawn in $2002(n=603)$, followed by discontinuations in $2003(n=463)$ and in $2004(n=407)$. Generic manufacturers consistently discontinued more SKUs each year, except in 2003 and 2005 (Table 2).

The majority $(70.71 \%)$ of discontinued SKUs fell into five ATC classes, i.e. anti-infectives for systemic use; nervous system; respiratory system; cardiovascular system; and alimentary tract and metabolism medicines. A total of 2610 discontinued SKUs fell into these classes, with $2002(n=406), 2003 \quad(n=324)$ and $2004(n=309)$ experiencing the highest number of SKU discontinuations (Table 3).

\begin{tabular}{llll}
\multicolumn{4}{l}{ Table 1. SKUs discontinued by designated manufacturer } \\
\hline Manufacturer & Product, $\boldsymbol{n}$ & SKUs discontinued, $\boldsymbol{n}$ & Mean (SD) \\
\hline Generic & 96 & 2145 & $22.34(58.11)$ \\
Innovator & 56 & 1546 & $27.61(41.89)$ \\
Combined & 152 & 3691 & $24.28(55.55)$ \\
\\
SKUs = stock-keeping units; SD = standard deviation.
\end{tabular}

Table 2. Innovator and generic SKUs discontinued per year

\begin{tabular}{|c|c|c|c|}
\hline Year & $\begin{array}{l}\text { Innovator } \\
\text { products } \\
\text { discontinued, } n\end{array}$ & $\begin{array}{l}\text { Generic } \\
\text { products } \\
\text { discontinued, } n\end{array}$ & Total, $N$ \\
\hline 2001 & 73 & 94 & 167 \\
\hline 2002 & 289 & 314 & 603 \\
\hline 2003 & 248 & 215 & 463 \\
\hline 2004 & 154 & 253 & 407 \\
\hline 2005 & 132 & 97 & 229 \\
\hline 2006 & 103 & 164 & 267 \\
\hline 2007 & 70 & 213 & 283 \\
\hline 2008 & 94 & 192 & 286 \\
\hline 2009 & 56 & 92 & 148 \\
\hline 2010 & 95 & 113 & 208 \\
\hline 2011 & 65 & 89 & 154 \\
\hline 2012 & 58 & 93 & 151 \\
\hline 2013 & 49 & 74 & 123 \\
\hline 2014 & 60 & 122 & 182 \\
\hline
\end{tabular}

Table 3. Discontinued SKUs classified by the ATC system

\begin{tabular}{ll}
\hline ATC classification & $\boldsymbol{n}(\%)$ \\
\hline Anti-infectives for systemic use & $848(22.97)$ \\
Nervous system & $578(15.66)$ \\
Respiratory system & $490(13.28)$ \\
Cardiovascular system & $368(9.97)$ \\
Alimentary tract and metabolism & $326(8.83)$ \\
Musculoskeletal system & $261(7.07)$ \\
Antineoplastic and immunomodulating agents & $156(4.23)$ \\
Dermatologicals & $138(3.74)$ \\
Genito-urinary system and sex hormones & $123(3.33)$ \\
Various & $107(2.90)$ \\
Sensory organs & $89(2.41)$ \\
Systemic hormonal preparations, excluding & $75(2.03)$ \\
sex hormones and insulins & \\
Blood and blood-forming organs & $67(1.82)$ \\
Antiparasitic products, insecticides and repellents & $65(1.76)$ \\
Total & $3691(100)$ \\
&
\end{tabular}


Medicine SKUs in the anti-infectives for systemic use class, accounted for the largest number of discontinued SKUs $(n=848)$. Generic manufacturers discontinued a consistently higher number of SKUs in this class from 2001 to 2014. The highest number of generic anti-infective SKUs were discontinued in $2002(n=68), 2004 \quad(n=79)$ and $2007(n=47)$. The highest number of innovator anti-infective SKUs discontinued occurred in $2002(n=23)$ and $2003(n=31)$. The highest number of discontinuations for cardiovascular medicines was evident in $2002(n=48), 2007(n=39)$ and 2010 $(n=37)$. Medicines acting on the reninangiotensin system was the largest class of such medicines that were discontinued $(n=94)$. This was followed by beta-blockers $(n=61)$, while the third-highest discontinued class was diuretics $(n=48)$.

The relationship between number of discontinued SKUs per year and increase in SEP was investigated, with the number of SKUs discontinued being the dependent variable (y). The regression line was determined to be as follows: SKUs discontinued: -14.06 (SEP increase) + 309.89 (Fig. 1). The regression line showed a negative relationship, with a Pearson's correlation coefficient $r-0.414 \quad(p=0.14)$. Our analysis showed that 10 SKUs (7 oncology molecules) that were withdrawn are no longer on the market, i.e. there was an identical molecule available after the product was discontinued (from the same or different manufacturer).

\section{Discussion}

The results from the analysis showed that generic and innovator manufacturers commercially withdrew SKUs during the study period, but prior to the implementation of the SEP legislation in 2004. Three generic manufacturers were responsible for withdrawing most of the SKUs. Generic manufacturers have a high vulnerability to price; therefore, a possible reason for the high number of generic SKU withdrawals could be price reductions, where it is no longer financially sustainable to produce the SKU. ${ }^{[13]}$

The highest number of SKUs were withdrawn in the years shortly before the implementation of SEP (2002 - 2004) consistent for generics and innovator medicines. In 2001, an industry body, the Pharmaceutical Manufacturers Association, withdrew its longstanding legal battle against the implementation of amendments to legislation that would enable pricing transparency, including SEP, which was finally legislated in April 2004. ${ }^{[4]}$ The high number of SKU withdrawals between 2002 and 2004 could have been due to a reaction by pharmaceutical manufacturers anticipating the imminent medicine price regulation by SEP legislation.

A strategy employed by pharmaceutical manufacturers to maximise profits (and a reason for commercial withdrawal), is SKU rationalisation. SKU rationalisation can be viewed as an effort by a company to maintain fewer SKUs of the same product, such that they only market the most profitable SKUs. This is especially true of the SA market, as SEP is applied to a single unit dose and not to pack-size; therefore, reduction in cost to the manufacturer is seen in terms of packaging components, material and packaging operations.

Anti-infective, cardiovascular and antiretroviral (ARV) medicines are three therapeutic classes associated with high usage and expenditure in the SA private health sector. ${ }^{[14]}$ Our analysis revealed that anti-infective and cardiovascular drugs

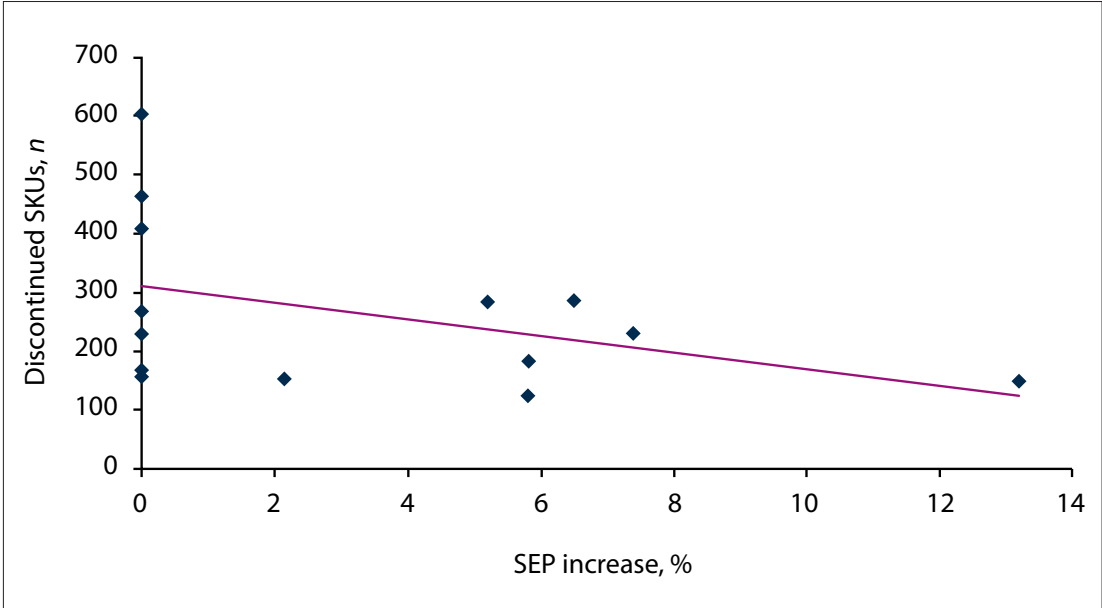

Fig. 1. Scatter plot and line between the dependent variable number of SKUs discontinued and the independent variable percentage SEP increase. (SKU = stock-keeping units; SEP = single exit pricing.) accounted for $22.97 \%$ and $9.97 \%$ of all SKU withdrawals, respectively. The majority of the withdrawn SKUs in the cardiovascular class was antihypertensives. This should be seen as hypertension having a very high prevalence (129.9/1 000) in SA. ${ }^{[14]}$ Antiinfective medicines follow a similar trend, with most withdrawn SKUs being the mostused antibiotics, i.e. beta-lactam antibiotics. ${ }^{[14]}$

Safety is another, albeit less common, reason for the voluntary withdrawal of a medicine from the market. In SA, between 2001 and 2014, very few medicines were completely withdrawn from the market owing to safety reasons. Two anti-inflammatory medicines, valdecoxib and rofecoxib, were withdrawn in 2004 owing to evidence that they increased the risk of heart attack and stroke. In 2011, an anti-diabetic medicine, rosiglitazone, and dextropropoxyphenecontaining products were withdrawn, because of cardiac concerns. The small number of safety withdrawals during the study period is consistent with findings of studies that analysed medicine withdrawal due to safety reasons. ${ }^{[15]}$

It may be plausible also to consider that changes to clinical guidelines, e.g. ARV and fixed-dose-combination guidelines, may have had an impact on the discontinuation of certain products. Furthermore, one should consider that some products may have been highly genericised, with many competitors for one molecule. This type of crowded market and downward pressure on price may be another reason why some SKUs were withdrawn, and that withdrawal was not primarily based on SEP policy.

SEP is further regulated by a fixed, allowable, maximum annual increase, which is published after consultation with the MPC, and with consideration of the average consumer price index (CPI ) for the preceding year, the average producer price index (PPI) for the preceding year, changes in the rates of foreign exchange and purchasing power parity, and international pricing information. ${ }^{[4]}$ A chief executive officer of a leading SA generic company remarked to the Business Day in January 2018 , in response to the annual SEP increase of $1.26 \%$, that 'continued pressure on the industry also leads to products being pulled from the market, which means a smaller variety of quality, affordable medicines for patients. ${ }^{[16]}$

Our analysis showed that a total of 3691 SKUs was discontinued during 2001 - 2014, with the highest number of withdrawals between 2002 and 2004 - shortly before the implementation of SEP. During the following years, there was a $4.19 \%$ yearly average price 
increase, with the MPC publishing a 0\% increase in 2004, 2005, 2006 and 2011. An increase of 5.2\% was published in 2007, almost 3 years after implementation of the pricing regulation. Bearing in mind the annual increases that were gazetted each year, it is interesting to note that from our analysis, generic medicines showed the highest number of product withdrawals during 2002 - 2008, with 1448 of a total of 2145 for that period. Innovator medicine withdrawals during the same period were also high, with 1090 of a total of 1546 . The highest SEP annual increase occurred in 2009 (13.2\%). In 2009, the innovator withdrawals from the market was the lowest since 2002.

In addition to SEP increases, the reduction of SKU withdrawals between 2009 and 2014 may have been driven by the strengthening of the ZAR against the USD. The ZAR showed great strength in recovery in 2009, trading at ZAR8.07 to the USD after lows hovering around ZAR10.00 to the USD at the end of 2008. The lower number of SKUs discontinued, could have been due to the stable exchange rate and SEP price increases that were gazetted during this time.

Our analysis included testing whether the yearly increase in SEP may have had a direct effect of the number of SKUs withdrawn during the study period. The linear regression used to assess if there was a correlation between the yearly SEP increase and the number of SKUs withdrawn, revealed a negative correlation, i.e. as the yearly percentage SEP increase improved, the number of SKU withdrawals decreased. This was further confirmed by Pearson's correlation coefficient $(r-0.414)$; however, the correlation was not statistically significant $(p=0.14)$.

Medicine pricing policies may have a dual impact on the market. Policies are typically aimed at making medicines more affordable for the patient; however, pricing policies may have a negative effect on medicine availability. The results show that SEP and a transparent pricing policy may have had an impact on SKU withdrawal from the market as a policy option prior to implementation.

In summary, our analysis shows that, although the anticipated introduction of SEP might have been the cause of product withdrawals, the limited annual price increases have not resulted in significantly increased withdrawals from the market, as predicted by manufacturers. Therefore, from this analysis it appears that the ongoing SEP regulations have not had a significant impact on access to medicines.

\section{Study limitations}

A limitation of the study was that the dataset did not allow for analysis of the availability or lack thereof of a discontinued molecule/ generic equivalent on the market after the discontinuation of one brand. This study analysed SKU withdrawals from the market and not entire products, i.e. a product may have remained on the market with fewer SKUs or one SKU. The impact on the patient in terms of cost, quality and medicine options has to be further analysed. The study could not determine if an SKU was withdrawn early on in the implementation phase and reintroduced later. Moreover, the study did not consider delayed entry into the market as a result of pricing policy interventions.

\section{Conclusions}

According to the World Health Organization/Health Action International project on medicine prices and availability, ${ }^{[17]}$ low prices can reduce the attractiveness of certain countries to manufacturers and importers, which may result in important products not being produced and marketed in a particular country or being marketed with substantial delays. The result of reduced product availability and its impact on the cost and quality of healthcare to the patient, need to be regularly monitored and evaluated to ascertain if direct price regulations achieve the intended outcomes. Other intended or unintended effects in pharmaceutical market dynamics should also be evaluated. Analysis of the number, timing and trend regarding new product launches would augment the body of evidence related to the market effects of SEP. This analysis would be valuable in exploring the impact of a legislated medicine pricing model on withdrawal and the effects of the availability of new medicines to the SA patient. Finally, while the anticipation of SEP in 2002 - 2004 led to higher product withdrawals before it was implemented, one cannot state that ongoing SEP implementation and the regulated annual increases have caused significant withdrawals of products from the market.

Declaration. The research for this study was done in partial fulfilment of the requirements for KN's MPharm (Pharmacoeconomics) degree at the University of KwaZulu-Natal.

\section{Acknowledgements. None.}

Author contributions. FS conceptualised the study. KN collected the data and undertook data analyses. FS verified the data and analyses. Both authors participated equally in the writing of the article.

Funding. None.

Conflicts of interest. FS serves on the National Medicines Pricing Committee.

\footnotetext{
1. Harris B, Goudge J, Ataguba JE, et al. Inequities in access to health care in South Africa. J Public Health Policy 2011;32(Suppl 1):S102-S123. https://doi.org/10.1057/jphp.2011.35

2. National Department of Health. National Drug Policy for South Africa. Pretoria: NDoH, 1996

3. South Africa. Medicines and Related Substances Act No. 90 of 1997.

4. South Africa. Medicines and Related Substances Act No. 101 of 1965.

5loor C, Dantés M, Graefenhain E. An Evaluation of Medicines Shortages in Europe with a More In-depth Review of These in France, Greece, Poland, Spain, and the United Kingdom. Switzerland: Birgli, 2013.

6. De Weerdt E, Simoens S, Hombroeckx L, Casteels M, Huys I. Causes of drug shortages in the legal pharmaceutical framework. Regul Toxicol Pharmacol 2015;71(2):251-258. https://doi.org/10.1016/j. pharmaceutical fram

ef Implementation of policy options on generics in 29 European countries - an overview. Generics
Intics Implementation of policy options on gencto Biosimilars Initiative J 2012;1(2):93-100

8. Vogler S, Kilpatrick K, Babar ZU. Analysis of medicine prices in New Zealand and 16 European countries. Value Health 2015;18(4):484-492. https://doi.org/10.1016/j.jval.2015.01.003

9. Babar Z-U-D, ed. Pharmaceutical Prices in the 21st Century. Switzerland: Springer International, 2015. https://doi.org/10.1007/978-3-319-12169-7

10. Ngozwana S. Policies to control prices of medicines: Does the South African experience have lessons for other African countries? In: Mackintosh M, Banda G, Tibandebage P, Wamae W, eds. Making Medicines in Africa. London: Palgrave Macmillan, 2016:203-223.

11. Pretorius D. The Impact of the Implementation of Single Exit Pricing for Pharmaceuticals in South Africa. Johannesburg: University of the Witwatersrand, 2011.

12. Naudé C, Luiz JM. An industry analysis of pharmaceutical production in South Africa. S Afr J Business Manage 2013;44(1):33-46. https://doi.org/10.4102/sajbm.v44i1.146

13. EGA Health Economics Committee. How to increase patient access to generic medicines in European healthcare systems. 2009. https://www.medicinesforeurope.com/wp-content/uploads/2016/03/Market_ Barriers_Report_FINAL_update_How_to_Increase_Patient_Access_to_Generic_Medicines.pdf Barriers_Report_FINAL_update_How_to_Increase_Patient_Access_to_Generic_Medicines
(accessed 9 September 2020).

4. Bester M, Badenhorst C, de Jager H. Medicines Review 2017. Centurion: Mediscor PBM, 2018

15. Clarke A, Deeks JJ, Shakir SA. An assessment of the publicly disseminated evidence of safety used in decisions to withdraw medicinal products from the UK and US markets. Drug Safety 2006;29(2):175-181. 16. Business Day. Motsoaledi's single exit price for medicines 'devastating. 2018. https://www.medicalbrief. co.za/archives/motsoaledis-single-exit-price-medicines-devastating (accessed 9 September 2020).

17. World Health Organization. Medicine prices, availability, affordability and price components. http:// haiweb.org/what-we-do/price-availability-affordability/price-availability-data/ (accessed 9 September
} 2020)

Accepted 17 November 2020 